\title{
Breastfeeding and Child Spacing among Women in South West Nigeria
}

\author{
Odu Bimbola Kemi ${ }^{1}$ and Ogunlade Joseph Olurotimi ${ }^{2}$ \\ ${ }^{1}$ Faculty of Education, University of Ado-Ekiti, Nigeria \\ ${ }^{2}$ Department of Educational Psychology, College of Education
}

\begin{abstract}
The study examined the relationship between breastfeeding behaviour and child spacing among women in South West Nigeria. If further investigated the frequency of sucking intensity of sucking, duration of amenorrhea and birth interval among women. The descriptive research design of the survey type was adopted for this study. The population for the study was made up of women with breastfeeding experience in South West Nigeria. The sample consists of 1.250 women sampled from three states in South West Nigeria. Multistage sampling technique was used to select the sample. The research instrument used to collect data from the respondents was a self designed questionnaire titled Breastfeeding Behaviour and Child Spacing Questionnaire (BBCSQ). The instrument was valid and reliable; it had a construct validity correlation coefficient of 0.76 and a reliability coefficient of 0.88 which was obtained at 0.05 level of significant. The study revealed that over eighty percent of women engaged in exclusive breastfeeding. It was found out that women generally have a positive attitude towards breastfeeding. The result of the study revealed that the birth interval was shorter with the average of two years compare to three to four years recorded in the old times. It was also found out that the importance of breastfeeding as a means of natural birth spacing was not well appreciated among women. Based on these findings, it was recommended that the health benefits of breastfeeding to the mother and child should be emphasized in the hospitals, maternity centres, churches, market and at village meetings. Health professionals - Doctors, Nurses, Midwives and even traditional birth attendants should be trained to encourage and support practices that will be conducive to breastfeeding.
\end{abstract}

\section{Introduction}

Breastfeeding is the act of feeding the baby from the breast. Breastfeeding behaviour according to Foster [10] is a social phenomenon related to breastfeeding activities which are under the control of norms and standards of social practices and expectation, they constitute activities which provide support for the mothers' choice to breastfeeding based on the behaviour that is healthiest for her and her new born, giving rise to what is commonly referred to as exclusive breastfeeding and supplementary breastfeeding practice. According to WHO [26] Breastfeeding confers substantial health benefits on both mother and child. For the infant, the principal advantages of breast milk are nutritional and immunological. For the mother, breastfeeding encourages the involution of the uterus and thus the rapid return of uterine tube which helps the mother to regain her natural shape. It promotes an affectionate bond between mother and child. It is economical and it is convenient. Also, through the proclatin elevating effect of nipple stimulation, breastfeeding delays the return of normal ovarian function and thereby lengthens the interval between births (McNeily [20], Hatcher [11], Orubuloye [23]. However, the contraceptive protection of breastfeeding may depend on the frequency and intensity of sucking which appears to be diminishing rapidly with time in Nigeria. Actual birth spacing is the result of a combination of factors such as parent's desired spacing as expressed through breastfeeding, mixed feeding and contraceptive use; other biological factors which may cause desired spacing not to be achieved (e.g. sub fecundity, poor health and nutritional status); periods of abstinence because of separation and other intermediate variables.

A number of different aspects of breastfeeding have been attributed to family planning size, child spacing and parity. In some cultures, there are taboos against women breastfeeding once they become pregnant. Some years ago, Henry [12] hypothesized that the number of children a woman has already had influence lactation duration if breastfeeding is used as a contraceptive.

Whereas the earlier studies provided qualitative description of social norms on postpartum behaviour, empirical studies that are demographic have yielded a lot of quantitative measures. These have given rise to a lot of models of produce estimates (Lesthaeghe and Page [18]; Bongaarts, [6] and attempted 
simplified methods of obtaining mean values of breastfeeding and other postpartum variables in surveys (Anderson, [3]. National and Local surveys have been more successful in looking at the dynamics of breastfeeding, if only because more detailed questions have provided information on many more factors of potential influence (Caldwell and Caldwell [7]; Van Esterik, [25]. The problems inherent in the demographic approach are the inadequacy of data sets to investigate underlying reasons for observed patterns; crudeness of the measurement of the parameter of breast-feeding behaviour itself and the challenges of accurate measurement and by the selection of questions to ask (Hull, [13].

In the biomedical literature, two main theories have been used to explain the breast-feeding fertility relationships, nutritional hypothesis and suckling pattern hypothesis. In the nutritional explanation, differences in the duration of postpartum in fecundity are attributed to fatness levels of the mother during the nutritionally streesful period of lactation. Nutrition may work through reduction in milk volume, and consequent increase in suckling by the infant. If this factor is to be determining one, behavioural studies of this sort have to look at dietary intake include food restrictions during pregnancy and lactation. However, studies have found only weak support for nutrition as an explanation for variations in lactation infecundity (Kukturk 16], Kurinij [15].

The hypothesis that infant suckling patterns are the key to suppression of ovulation is better substantiated. The precise mechanism of operations has not been identified. Suggestions about aspects of suckling patterns which are responsible for the effect include overall frequency of nursing, total nursing time between bouts and intensity of suckling which assumed to be important but difficult to measure (Langs and Lawrence [17].

Various literatures have provided evidence for a positive association between the duration of breastfeeding and the length of birth interval. There are three components of birth interval namely postpartum amenorrhea, menstruating interval and gestation period. It is an established fact that breastfeeding, menses return shortly after birth Cronenwelt [8]. As the duration of breastfeeding increases so does the amenorrhea interval. With lactation, mean amenorrhea intervals from one to two years are observed in both developing and developed countries Dungry [9]; Lundgren 2001 [19].

\section{Research Rationale}

It is observed that the incidence and duration of breastfeeding and its associated practice of post partum amenorrhea are declining among women in south west Nigeria, which tends to shorten the length of birth interval. The problem now is that if breastfeeding and its influence on fertility in not well attended to it may affect the health of the mother and children beyond control.

From literature, it seems that a very high percentage of women in south west Nigeria do not commence breastfeeding immediately after birth and that majority might not be conforming with WHO/UNICEF [24] declaration that women must breastfeed exclusively for the first six months of life. Meanwhile research has shown that children born too soon after the previous birth are at the risk of dying at an early age. This simply amounts to putting the health of the child and the mother at an unnecessary risk.

To find solution to the problem of decline in breastfeeding and child spacing among women in Nigeria, the following general questions were raised:

1. What is the prevalent breastfeeding behaviour among women in south west Nigeria

2. What is the frequency of breastfeeding among women in south west Nigeria

Hypotheses:

1. There is no significant relationship between breastfeeding behaviour and child spacing style of women in South West Nigeria.

2. There is no significant relationship between frequent sucking and duration of Amenorrhea (Child Spacing).

\section{Methodology}

The study made use of descriptive design of the survey type. The population consisted of all the women in South West of Nigeria. The sample consisted of 1250 women who were selected using stratified, purposive and simple random sampling techniques. The research instrument consisted of two sections, section A consist social characteristic of respondents such as religion, sex of the children, educational qualifications, age, location of residence and some background information such as birth interval, resumption of menstruation. Section B consisted of twenty items on breastfeeding behaviour and child spacing. The research instrument was validated while the reliability of 0.88 was obtained using split half method of establishing reliability. Research assistants and the researchers administered the questionnaire. The data was analysed using frequency count, percentages for the describing the data, Pearson Product Moment Correlation and Chisquare were using to test the hypotheses at 0.05 level of significance. 


\section{Result}

\subsection{Descriptive Analysis}

4.1.1. Question 1: What is the prevalent breastfeeding behaviour among women in South West Nigeria?

In order to answer the question, responses on items relating to exclusive breastfeeding, mixed feeding and bottle feeding were categorised and collapsed into "low", Moderate and High for exclusive breastfeeding, "Never and "one month" were collapsed to form "low", exclusive breastfeeding duration ranging between 2 to 4 months were categorized as "moderate" while those ranging between 5 to 6 months were grouped as "High

As regards mixed feeding and bottle feeding, the subjects responses were collapsed from 7 points scale to 3 point scale of "low", moderate and "High". The result is shown in Table 1.

Table 1. Frequency and percentage distribution showing the prevalent Breastfeeding behavior among women in South West Nigeria

\begin{tabular}{|l|l|l|l|l|l|l|l|l|l|}
\hline & \multicolumn{2}{|c|}{ Low } & \multicolumn{2}{|l|}{ Moderate } & \multicolumn{3}{|c|}{ High } & \multicolumn{3}{|l|}{} \\
\hline $\begin{array}{l}\text { Breastfeeding } \\
\text { Behaviour }\end{array}$ & $\mathrm{F}$ & $\%$ & $\mathrm{~F}$ & $\%$ & $\mathrm{~F}$ & $\%$ & $\mathrm{~N}$ & $\%$ & Rank \\
\hline $\begin{array}{l}\text { Exclusive } \\
\text { Breastfeeding }\end{array}$ & 41 & 6.4 & 168 & 25.8 & 439 & 67.8 & 648 & 51.8 & $1^{\text {st }}$ \\
\hline $\begin{array}{l}\text { Mixed } \\
\text { Feeding }\end{array}$ & 72 & 25.3 & 209 & 73.2 & 5 & 1.5 & 286 & 22.9 & $3^{\text {rd }}$ \\
\hline $\begin{array}{l}\text { Bottle } \\
\text { Feeding }\end{array}$ & 208 & 65.8 & 89 & 28.2 & 19 & 6.0 & 316 & 25.3 & $2^{\text {nd }}$ \\
\hline
\end{tabular}

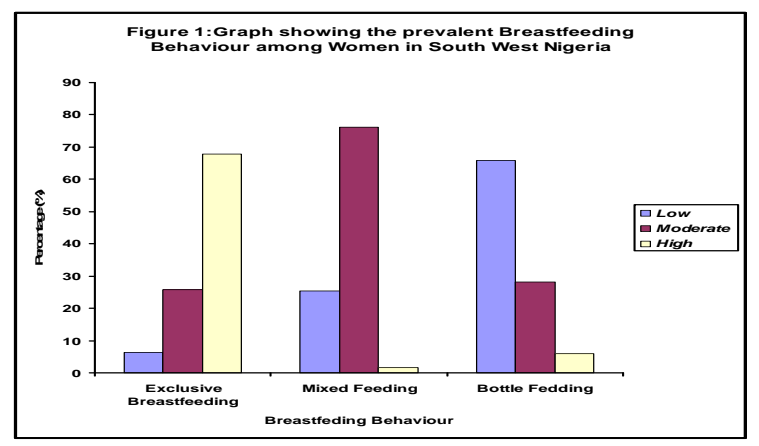

Figure 1. Graph showing the prevalent Breastfeeding Behaviour among women in South West Nigeria

Table 1 and figure 1 shows that exclusive breastfeeding was the most prevalent breastfeeding behaviour among women in South West Nigeria as 648 (51.8\%) of the respondents approved of it, this was followed by bottle feeding as 316 (25.3\%) respondents responded positively while mixed feeding was the least prevalent as indicated by the response of 256 (22.9\%) respondents. Furthermore it was revealed that exclusive breastfeeding is highly practised $($ Low $=6.4 \%)$, moderate $=25.8 \%$, High (67.8\%), Mixed feeding (Low 25.3\%, moderate = $76.2 \%$, High $=1.5 \%$ ) was moderately practised while bottle feeding (Low $=65.8 \%$, Moderate $=$ $28.2 \%$, High $=6 \%$ ) was least practised by women in the South West Nigeria.

4.1.2. Question 2: What is the frequency of breastfeeding among women in South West Nigeria?

To answer the question, responses on items 15 an 16 of the questionnaire which depicted the frequency of breastfeeding during the day and night were use. The result is shown in table 2 .

Table 2. Frequency and percentage distribution showing the prevalent Breastfeeding behavior among women in South West Nigeria

\begin{tabular}{|c|l|l|l|}
\hline Period & $\begin{array}{l}\text { Frequency of } \\
\text { Breastfeeding }\end{array}$ & Frequency & Percentage \\
\hline \multirow{4}{*}{} & Not Sure & 503 & 40.2 \\
\cline { 2 - 4 } & About 1-5times & 20 & 1.6 \\
\cline { 2 - 4 } & About 6-10times & 318 & 25.4 \\
\cline { 2 - 4 } & About 11-15times & 125 & 10.0 \\
\cline { 2 - 4 } & About 16-20times & 284 & 22.7 \\
\hline \multirow{4}{*}{$\underset{*}{*}$} & Not Sure & 96 & 7.7 \\
\cline { 2 - 4 } & About 1-5times & 539 & 43.1 \\
\cline { 2 - 4 } & About 6-10times & 107 & 8.6 \\
\cline { 2 - 4 } & About 11-15times & 385 & 30.8 \\
\cline { 2 - 4 } & About 16-20times & 123 & 9.8 \\
\hline
\end{tabular}

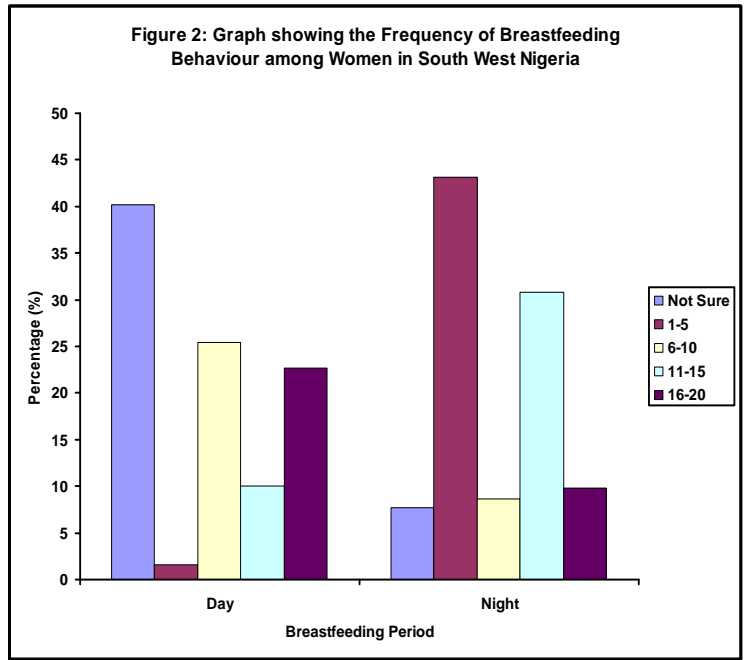

Figure 2. Graph showing the frequency of Breastfeeding among women in South Nigeria

The result of Table 2 and Figure 2 reveal that 20 (1.6\%) of the total sample breastfeed their babies ranging from 1-5 times during the day, 318 (25.4\%) breastfeed between 6 and 10times, 125(10\%) between 11 and 15 times, 284 (22.7\%) breastfeed between 16 and 20 times while 503 (40.2\%) were not certain about the frequency of breastfeeding during the day time

Responses on frequency of breastfeeding during the night by women in South West Nigeria showed 
that $539(43.1 \%)$ of the subjects put their babies to breastmilk between 1 and 5 times, 107 (8.6\%) breastfeed between 6 and 10 times in the night, 385 (30.8\%) had their frequency to breastfeeding ranging from 11 to 15 times, 123 ( $9.8 \%$ ) breastfeed between 16 and 20times in the night while only 96(7.7\%) could not ascertain their frequency of breastfeeding in the night.

The result clearly shows that more of the breastfeeding activities took place during the night compared to day time as frequency of breastfeeding increased in the night. This is so because mothers go to work during the day.

\subsection{Hypotheses Testing}

This section deals with the testing of the nine hypotheses generated for the study using appropriate statistical tools and tested at 0.05 level of significance

There is no significant relationship between breastfeeding behaviour and child spacing of women in South West Nigeria

To analyse the hypotheses, items relating to breastfeeding behaviour and child spacing were computed in each case. The two variables were subjected to Pearson Product Moment Correlation analysis at 0.05 level of significance. The result is presented in Table 3.

Table 3. Pearson Correlation of Breastfeeding Behavior and Child Spacing

\begin{tabular}{|l|l|l|c|}
\hline Variable & N & r-cal & r-table \\
\hline $\begin{array}{l}\text { Breastfeeding Behavior } \\
\text { Child Spacing }\end{array}$ & 1250 & 0.263 & 0.195 \\
\hline
\end{tabular}

Table 3 shows that $r$-cal (263) is greater than $r-$ table (.195) at 0.05 level of significance. The null hypothesis is rejected. Therefore, there is a significant relationship between breastfeeding behaviour and child spacing of women in South West Nigeria.

Hypotheses 2

There is no significant relationship between frequency of sucking and duration of Amenorrhea (Child Spacing).

To analyse the hypothesis, items on frequency of sucking (day and night) were cross tabulated with duration of amenorrhea. The result of chi-square is presented in Table 4. (please see end of paper)

Table 4 shows the relationship between frequency of sucking and duration amenorrhea. The null hypotheses is rejected since X2cal (150.912, 109.536, $\mathrm{P}<0.05$ )

Therefore, there is a significant relationship between frequency of sucking and duration of Amenorrhea (Child spacing). The result also reveals that duration of amenorrhea increases with increase in the frequency of sucking e.g. 81 out of 125 respondents who breastfeed their babies between 11 and 15 times during the day resume menstruation after 7 months. Similarly, 204 out of 284 respondents who breastfeed their babies 16-20 times during the day time resume menstruation after 7 months of delivery.

\section{Discussion}

The study has examined the relationship between breastfeeding behaviour and child spacing among women in southwest Nigeria. The findings of this study were based on thorough examination of breastfeeding behaviour of women using percentage. Responses of their breastfeeding behaviour revealed that the behaviour of women was positive. It was discovered not less than $67.8 \%$ of the women practice exclusive breastfeeding which negate the observation of the researcher that women seem not breastfeeding their babies exclusively in the contemporary times. In order words, this result suggests that most of the women were of desirable behaviour, all other hindrances notwithstanding.

This finding is consistent with the existing literature that breast milk is an excellent source of nutrition for the baby, and promotes an affectionate bond between mother and child. Moreso that it lengthens the interval between births. (Hatcher [11], Mc Neily [20], Orubuloye [23], Foster [10], Alvarex [1] This could further be explained that at group level women believe that it is a natural responsibility of women to breastfeed their babies and at individual level each woman might have developed positive self esteem that will enhance her intra and inter personal breastfeeding behaviour. This view is supports by the submission of UNICEF and WHO [24] that breastfeeding experience may be strange tingling and exciting but in a day or two mothers and babies will surely find a comfortable and enjoyable routine mutually beneficial to both. The response of the subjects in the study to pattern of breastfeeding is favourable to exclusive breastfeeding as the best means of feeding baby which support the argument of Alvarex [2] WHO [27], that human milk is ideal for the baby, cow milk for the calf and that breast milk is the best food that a child will ever have. All substitutes including cow milk, milk powder solution and the cereal gruels are inferior.

Moreover, it is revealed that the frequency of breastfeeding is very high among women in South West Nigeria, that is, women provide virtually all the baby's nutrition from the breast. On the average most of the breastfeeding activities were done in the night. This may not be so strange since most of our women are engaged in different works or activity during the day which might not allow them to breastfeed properly. Therefore the night could be a better time even when the mother is asleep some babies do suck till they sleep off. But some were not sure about the 
number of times they do it in the night and during the days. This could mean that these set of women are those who see breastfeeding as a waste of time or making breast to sag or that breastfeeding should be relegated to the rural women or those who cannot afford to buy commercial milk.

The finding of an aspect of this study which reported a highly favourable attitude to full breastfeeding is supported by Orubuloye [22] who indicated that children were exclusively breastfed. This view was equally corroborated by the submission of UNICEF [24], Ayadi [4], Alvarex [1] when they reported that breast milk is the best possible food and drink for babies in the first four to six months of life and universally breast milk is naturally accepted as food for babies because cow milk is not suitable to human infant digestive tract and hence it has to be diluted and made into formula.

It was also discovered that a relationship exist between breastfeeding and child spacing. This finding is consistent with existing literature that lactation or act of breastfeeding provides a degree of contraceptive protection through the postpartum amenorrhea cause by the elevated proclatin level which inhibits the release of pituitary and ovarian homorne which delay ovulation Orubuloye [23] and Babe [5].

This process is call Lactational Amenorrhea Method (LAM) although this contraceptive protection of breastfeeding depends on the frequency and intensity of the infants on the breast. This is better explained through the description of Kipley [14] that such breastfeeding is the kind of nursing that most effectively space babies, nursing on cue, keeping baby close, providing all nourishment and liquids at the best for the six to eight months and nursing to comfort the baby, conclusively if the routine is followed strictly breastfeeding can be used as interim family planning method and a means of spacing birth.

Furthermore the study sought to find out if a significant relationship exists between frequency of sucking and duration of Amenorrhea. The result revealed that there is a significant relationship between frequency of sucking and duration of Amenorrhea. This result was supported by Kipley [14] that the contraceptive protection of breastfeeding normally depends on the frequency an intensity of sucking of the infant on the breast. He explain further that such breastfeeding behaviour is a kind of nursing that most effectively space babies such as nursing on cue, keeping baby close, providing all nourishment and liquid at the breast for the first four to eight months. Orubuloye [22] and Ogunmodimu [28] corroborate this view by asserting that if breastfeeding is supplemented the amount of proclatin produced mill be insufficient to delay ovulation then the lack of menstrual period which breastfeeding mothers experience that enable them to recover from the birth of child which guranted her unlikeness to conceive a second baby quickly is at stake.

WHO [27] \& UNICEF [24] agreed that for lactation amenorrhea to be used as reliable contraceptive, the baby must receive all of its nutrition from the breast, no bottle supplements or solid foods and the baby feed at least every four hour during the day and every six hours at night. Babe [5] concluded that a prolonged breastfeeding associated with sucking pattern is said to be an influencing factor on duration or amenorrhea.

A possible reason for the observed relationship between frequency of sucking and duration of amenorrhea could be attributed to the submission of Orubuloye [23] and Babe [5] who noted that medical evidence indicated that lactation provides a degree of contraceptive protection though the post partum amenorrhea cause by the elevated proclatin is responsible for the secretion of milk in the breast which produces delay in ovulation. This argument was further emphasized by Alvarex [2] that the inhibitory effect of protection disrupts the carefully balanced release of pituitary and ovarian hormones responsible for the ovulation and the resumption of normal menstruation cycles.

The study also shows that there is a significant relationship between duration of breastfeeding and birth interval among women.

This finding agrees with the view of Orubuloye [23] who confirmed that in tropical Africa, it is the intensive and prolonged breastfeeding practice that is responsible for the long interbirth, which had male fertility in these societies far below the biological maximum of $15.3 \%$ children per woman. He explained further that breastfeeding is reinforced by the custom of child spacing with reference to Yoruba context where marriage is almost universal to the extent that the use of contraception appeared to be low. Abortion is not allowed or practiced openly, the difference in fertility to postpartum unsuceptible periods that is breastfeeding practice determines an ovulation and amenorrhea, in the analysis of the determinant of birth interval by Rindfuss, [29] he found out that there is a significant and important difference in child spacing for the following variable ethnicity, age at first born, breastfeeding duration and sex of child preceding birth.

Oluwadare [30] also hypothesized breastfeeding as one of the factor that affects the length of birth interval. Finally, Newman and Pitman [21] posited that actual birth spacing is the result of a combination of factors such as parents' desire, spacing as expressed through breastfeeding. It is an established fact that breastfeeding is the principal determinant of the duration of postpartum amenorrhea. In the absence of breastfeeding, menses return shortly after birth Corne welt, [8] as the 
duration of breastfeeding increase, so does the amenorrhea interval.

\section{Recommendations}

Based on the findings of the study it is hereby recommended that:

1. Counsellors can provide information on breastfeeding to women who do not start breastfeeding half an hour after delivery. Media campaign could be used to spread information as well as increase awareness, which may lead to quick initiation of breastfeeding. Such as published books, Video Tape, Posters and brochures.

2. The Health benefits of breast milk should be emphasized in the hospitals, maternity centres, churches, markets and at village meetings. As much as possible whenever and wherever women are meeting, opportunity should be sought to instruct them on the benefits of breastfeeding.

3. That health worker, Counselling and other concern bodies should be able to form breastfeeding support groups where mother can be referrd to on discharged from the hospital or clinic. This body will also organize campaign in Nigeria to encourage and publicize the benefit of breastfeeding to the nursing mother and her child and to the society at large.

4. It is also recommended that worker should breastfeed exclusively for the minimum of 6 months to enhance good health for her self and her baby at the same time to be able to have the knowledge and understanding of the effect of breastfeeding on her facility.

5. reformation of LAM as a family planning method must be Emphasised. It is also recommended that government should introduce an intervention programmes that will involve training staff in hospitals to p rovide counseling on the benefits and behavioural skill of breastfeeding.

\section{References}

[1] Alvarex, X.Y. (2002). Breast milk immunology: A Frontier in infant nutrition. American Journal Dissertation. Child 133:83.

[2] Alverex, X.Y. (1987). Breastfeeding in the work place. Rediatric clinic of work America pubmed Abstract.

[3] Anderson, C.O. (2003). Effect of community based peer counselors on exclusive breastfeeding practices in Dhaka, Bangladesh: A randomized controlled trial; The Lancet: 356(92 42), 1643-1647.

[4] Ayadi, E.A. (1994). Infant model for breast feeding in mahart Nakhon Ratchasima Hospital southeast Asean. Journal of Tropical Medicine and Public Health 23(3), 439-443.
[5] Babe, C.F. (1997). Breast feeding and birth interval in Burundi. Medicine Tropiale

[6] Bongaart, J. (1982). 'A framework for analyzing the proximate determinants of fertility ', Population and Development Review 4, (1), 105 - 132.

[7] Caldwell, J. C \& Caldwell, P.C. (2000). The role of marital sexual abstinence in determining fertility: A study of the Yoruba of Nigeria' Population Studies, 31, 193-217.

[8] Cronet-wel, C.S. (2001) Bellagio consensus statement breastfeeding as a family planning method lancet, 2,2041205.

[9] Dungy, E.O. (1998) Effect of discharge sample on duration of breastfeeding. Pediatrics, (2): 233-237.

[10] Foster, M.S. (2006) Women's decision about breastfeeding and maternal employment. Journal of Marriage and the family 58, 239-251.

[11] Hatcher R.A. (2004) Contraceptive technology, New York; Living Publishers.

[12] Henry B.F. (1988). La leche league in the United States: A Key to successful Breastfeeding in non supportive culture. Journal of Nurse-Midwifery. 21(1), 2026.

[13] Hull, T.H. \& Hull V.J. (1997): "The relation of economic class and fertility: An analysis of some Indonesian data” Population Studies, _31 (1) 43-57.

[14] Kippley, S.M (1999) Breastfeeding and natural child spacing. Cincinnati, OH: CCL.

[15] Kurinij, N (2003) Predicting duration of breastfeeding in a group of urban primiparae. Ecology of Food and Nutrition, 15,281-291.

[16] Kokturk T. \& Zetterstrorm, R (2002). The promotion of breastfeeding and maternal attitudes. Acta Paediatrical Scandinavica, 78,817-823.

[17] Lang, S. Lawrence, C.J, \& Orme R.E (2001). Cup feeding: an alternative method of infant feeding. Archives of Disease in Childhood, 71,365- 269.

[18] Lesthaghe, R. \& Page, D. (1981) Breastfeeding: The best investment. Journal of Tropical Pediatrics.

[19] Lundgren, B.F. (2001) Improving the lost effectiveness of breastfeeding promotion in maternity services. Journal of Human Lactation.

[20] Mcneilly, A.S., (1999): "Relationship of feeding patterns, proclaction and resumption of ovulation postpartum” in G.I. Zatuchini, M.H. Labbok \& J. Sciarra (Eds), Research frontiers in fertility regulation. New York Herper and Row Hagerstown, New York. (Pp 102-126).

[21] Newman, J. \& Pitman, T. (2001) The ultimate breastfeeding book of answers. Roseville, C.A: Prima Publishing. 
[22] Orubuloye, I.O. (1979): "The significance of breastfeeding on fertility and mortality. Journal of Tropical Pediatric and Environmental Child Health.

[23] Orubuloye, I.O. (1982): "Rural - urban fertility differential among the Yorubas of Nigeria". In Population and Economic development in Nigeria in the 1980s. (Pp 28-40) New York:

[24] UNICEF (2002) Lactational amenorrhea method (LAM) Publication of Georgia University, Institute fro reproductive Health.

[25] Van Estrick, P. \& Greiner T. (1991) "Breastfeeding and woman's work: Constraints and opportunities". Studies in Family Planning, 12. (4), 184 - 197.

[26] WHO (2002) Essentials of contraceptive technology. John Hopkins Program for International Education in Reproduction Health.

[27] WHO (2004) Preliminary report of the WHO collaborative study on breastfeeding (MCH / 79. 3): Geneva.

[28] Ogunmodimu E.F. (2001). Consensus statement on the use of breastfeeding as a family planning method. Contraception 1989:39,477-96.

[29] Rindfuss, R.R. (1997) Pacifier rise and short breastfeeding duration: Cause consequences or coincidence? Pediztrics, 99(3), 445 - 453.
[30] Oluwadare, C.T. (1999) Maternal health behaviour in rural Ekiti Review of Growth and Change. 1, 1:9-15. 
Table 4. Chi-square (x2) Analysis showing frequency of sucking and duration of Amenorrhea

\begin{tabular}{|c|c|c|c|c|c|c|c|c|}
\hline & & \multicolumn{7}{|c|}{ Duration of Amenorrhea } \\
\hline \multirow{7}{*}{ 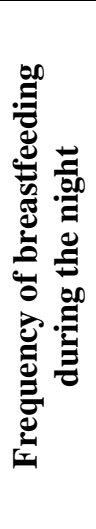 } & & $\begin{array}{l}\text { Immediately } \\
\text { after birth }\end{array}$ & $1-3$ & $4-6$ & 7months+ & Total & $\mathrm{X}^{2} \mathrm{cal}$ & $\begin{array}{l}X^{2}- \\
\text { Tab }\end{array}$ \\
\hline & $\begin{array}{l}\text { Not } \\
\text { Sure }\end{array}$ & $5(6.5)$ & $8(12.1)$ & $43(28)$ & $40(49)$ & 96(96) & \multirow[t]{4}{*}{10.9 .536} & \multirow[t]{4}{*}{100} \\
\hline & $\begin{array}{l}1-5 \\
\text { times }\end{array}$ & $26(36.7)$ & $84(67.7)$ & 205(157.3) & $224(277.2)$ & 539(539) & & \\
\hline & $\begin{array}{l}6-10 \\
\text { times }\end{array}$ & $5(7.2)$ & $15(13.4)$ & $17(31.2)$ & $70(55)$ & $107(107)$ & & \\
\hline & $\begin{array}{l}11-15 \\
\text { times }\end{array}$ & $40(26.2)$ & $29(48.4)$ & 63(112.4) & 253(198) & $385(385)$ & & \\
\hline & $\begin{array}{l}16-20 \\
\text { times }\end{array}$ & $9(8.36)$ & $21(15.5)$ & $37(35.9)$ & $56(63.3)$ & $123(123)$ & & \\
\hline & Total & $85(85)$ & $157(157)$ & $365(365)$ & $643(643)$ & $1250(1250)$ & & \\
\hline & $\begin{array}{l}\text { Not } \\
\text { sure }\end{array}$ & $42(34.2)$ & $71(63.2)$ & 134(146.9) & 256(258.7) & $503(503)$ & & \\
\hline 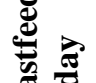 & $\begin{array}{l}1-5 \\
\text { times }\end{array}$ & $2(1.36)$ & $6(2.5)$ & $4(5.84)$ & $8(10.3)$ & $20(20)$ & & \\
\hline 苋 & $\begin{array}{l}6-10 \\
\text { times }\end{array}$ & $18(21.6)$ & $50(39.9)$ & 156(92.9) & $94(165.6)$ & $318(318)$ & & స్ \\
\hline 글 & $\begin{array}{l}11-15 \\
\text { times }\end{array}$ & $4(8.5)$ & $6(15.7)$ & $34(36.5)$ & $81(64.3)$ & $125(125)$ & & 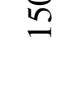 \\
\hline تٍِّ & $\begin{array}{l}16-20 \\
\text { times }\end{array}$ & 19(19.3) & $24(35.7)$ & $37(82.9)$ & $204(146.1)$ & $284(284)$ & & \\
\hline & Total & $85(6.8)$ & $157(12.6)$ & $365(29.2)$ & 643(51.4) & $1250(100)$ & & \\
\hline
\end{tabular}

$\mathrm{P}<0.05 \mathrm{X}^{2}$ table $=100, \mathrm{df}=12$ 